\title{
The Power of Electronic - Digital Media at the Event on Cyber Bullying
}

\author{
Konstantinos Zimianitis \\ Athens, Greece \\ Email: zimkostas [AT] yahoo.gr
}

\begin{abstract}
The rise of technology in recent years has made the internet a widely used medium for all ages and social groups. It enables users to communicate, exchange information, be informed, work and be entertained. Through the internet, users can express their views and ideas, engage in art, express their thoughts, make purchases, search for

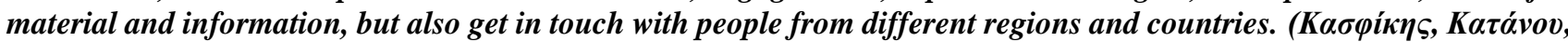

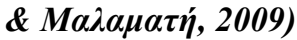

Keywords--- Cyber bullying, perpetrators, victims, digital media

\section{PREFACE}

The use of the internet has preoccupied scientists and mental health professionals, as many times the dangers that lie in wait cause problems for users, with consequences in various areas of their lives. The internet can turn into a negative tool in the hands of users who intend to harm another person. In particular, electronic - digital media can be used against a person and expose material and information about them and their life, for which they do not agree with its publication.

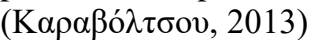

Cyber bullying is a phenomenon that has been of great interest in recent years due to the way it affects people's

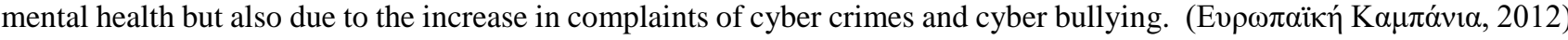

According to Belsey (2005), cyber bullying refers to the use of Information and Communication Technologies and is related to a specific, hostile behaviour from one person to another with the aim of harming it. (Belsey, 2005) These phenomena take place in various electronic-digital media, such as social networking sites, blogs, micro-blogs, platforms, websites and online games that allow the exchange of comments and content. (Li, Gross, \& Smith, 2012)

\section{THE PHENOMENON OF CYBER BULLYING}

Cyber bullying is a "modern" continuation of the traditional bullying that has developed in the virtual world and is growing rapidly as the use of the internet continues to grow. (Kov́ $\rho \tau \eta, 2003$ ) A key feature is the anonymity it offers to users, as electronic media can be used without revealing the users' identities. (Li, Gross, \& Smith, 2012)

According to Nikolopoulos (2009), the very nature of the media contributes to the increase of the phenomenon since their dissemination and the way one can handle them facilitate the conduct of malicious actions. Also, the fact that the speed of information dissemination is extremely fast, combined with the fact that information stays "forever" on the internet are reasons that make cyber bullying dangerous. (Kowalski, Limber, \& Agatston, 2012)

Cyber bullying has no specific geographical boundaries because the internet can be used by anyone wherever they are, at any time and in any way they want. (Kowalski, Limber, \& Agatston, 2012) The phenomenon is exacerbated by the fact that the perpetrators do not really come in contact with the victims, due to the distance of the internet and so their

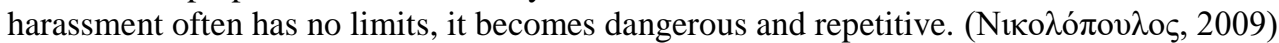

The characteristics of cyber bullying refer to the intentional behaviour of the perpetrator, the harm they want to cause to the victim and the means they use to promote information, comments or material to the detriment of the victim, while maintaining their anonymity. Emails, chat rooms, social media websites, messaging programs, websites, blogs, and any other platform that allows commenting, promoting material and content are used as the media for cyber bullying. The perpetrators "hide" behind the digital media and declare false information, since they are not controlled and can easily create fake identities. (Patchin \& Hinduja, 2010)

Any action aimed at deceiving, harming, or damaging a user is considered a form of cyber bullying. In particular, sending texts, messages, videos, and comments with threatening or malicious content can be sent directly to the victim with the aim of harming them or to a group of people, in order to become part of the bullying. Posting personal or sensitive information to various recipients or blogs and social networking sites has immediate consequences for the victim, as the content remains online for a long time and is often impossible to delete. (Feinberg \& Robey, 2009)

Also, the sending of viruses or programs, which are intended to cause some harm to the user or to restrict their activity on the internet is used as a means of threat. Also, hacking a personal account or using another person's name is 
considered a form of cyber bullying, as it is used to spread false information or cause problems to users. Finally, falsifying photos or videos depicting a particular person and posting them without their consent is just as dangerous and reprehensible. (Feinberg \& Robey, 2009)

\section{THE CONSEQUENCES OF CYBER BULLYING}

Cyber bullying is a dangerous behaviour for everyone involved, as it causes emotional problems, affecting the victim's psychology. The psychological violence that victims feel is as intense and dangerous as traditional bullying. Victims often come to despair because they do not know how to solve the problem. Thus, they present with depression, increased stress, reduced school or work performance, problems concentrating and avoiding activities that used to please them. They are also more likely to drop out of school or work and show low self-esteem, antisocial behaviour, anger and extreme thoughts.(Feinberg \& Robey, 2009)

Research has shown that more than 13 million children and adolescents are victims of cyber bullying each year. Surveys show that many young people have been harassed by someone online. This is why it is important for parents to monitor their children's online activity, as well as for teachers to be able to inform children about cyber bullying and prevention strategies.(McQuade \& Sampat, 2008)

Cyber bullying happens most of the time when children surf the internet at home, but it can also happen during school. The consequences vary depending on the event in question, the character, and the social environment of the victim. Thus, they are not the same for everyone. Some are more vulnerable and some less so.(Feinberg \& Robey, 2009)

Many young people who have the support of family and friends can deal better with cyber bullying and make the right decisions through help and the right guidance. On the contrary, those who are more vulnerable do not manage the phenomenon properly, since most of the time they hide their problem from their family and friends and cannot deal with it. For this reason, it is important for young people to contact an adult directly and report the problem.(Adams, 2010)

\section{RESEARCH RELATED TO CYBER BULLYING}

A UK study by Smith, Mahdavi, Carvalho and Tippett (2006) found that $22 \%$ of the students surveyed had experienced cyber bullying at least in recent months. Bullying had taken place through text messages on social media, mostly, but also via e-mails. Girls had higher rates than boys. The children, according to the investigation, had not spoken about the cyber bullying they had suffered.(Smith, Mahdavi, Carvalho, \&Tippett, 2006)

Also, another study conducted in the USA by Ybarra and Mitchell (2004) showed that teenagers who used the Internet had become both perpetrators and victims of cyber bullying. Specifically, $12 \%$ were perpetrators, $4 \%$ victims, while $3 \%$ admitted that they had both roles.(Ybarra \& Mitchell, 2004)

A survey on cyber bullying at European level, conducted in 2011, reported that 1 in 6 teenagers in Europe has been the victim of cyber bullying. Specifically, $6 \%$ of all children reported being bullied, while $3 \%$ admitted to having bullied other users.(Eu Kids On Line, 2011)

In Greece in 2015, Safe Line pointed out that the number of complaints it had received reached four thousand. Despite the changes made to the legislation on issues related to the internet and user safety in 2014, and the criminalization of cyber bullying in 2015, there were many complaints. The complaints concerned the internet and the violation of personal data, mainly through social media, such as Facebook, Instagram, etc. (SafeLine, 2015)

Didden et al. (2009) in their research examined cyber bullying through the internet and mobile phones in 114 students of a special school in the Netherlands. The results of the research divided the students into four categories. The first concerned the student-perpetrators, the second the student-victims, the third the students with the role of perpetrator victim and the fourth the students who had no relation with cyber bullying. $22 \%$ had been bullied via mobile phones, while $85 \%$ said they had taken on the role of both perpetrator and victim. Students sent or received messages anonymously, mainly through their mobile phones. (Didden, et al., 2009)

Another study, which studied the student perceptions on cyber bullying in two US states, showed that the effects were serious for the victims' mental health, as they experienced anxiety, depression and emotional problems. The researcher stated that the responsibility of teachers is great for the prevention and treatment of the phenomenon. (Guckert, 2013)

Barringer-Brown (2015) investigated cyber bullying in adolescent students in the Netherlands who were bullying or got bullied on social media. The results showed that there is a strong correlation between cyber bullying and IQ. The researcher stated that the victims had emotional problems and concluded that special ways are needed, which will help to deal with the phenomenon mainly with the cooperation and involvement of parents.(Barringer-Brown, 2015)

Finally, another New Jersey study examining cyber bullying that involved the parents' attitudes toward cyber bullying, found that parents of students with disabilities or learning disabilities were aware of the phenomenon and were trying to protect their children. The researcher claimed that the parents of these students had been exposed to cyber bullying. She also stressed that the parents of the other children did not have the appropriate information or education about the consequences of cyber bullying and therefore, did not control their children's online activity.(Horakh, 2012).

\section{FINAL NOTE}


As it turned out, the internet is a very popular medium, since most of the population uses computers and especially social media. Its increasing use on the one hand offers benefits in human communication, since it is performed easily, quickly and effortlessly, but on the other hand, it also carries serious risks.(Nıколó

Cyber bullying as a form of bullying has reached alarming proportions, as the more the internet is used, the more the effects of cyber bullying increase. The perpetrators and victims can be either young children or teenagers. However, even adults can play the role of perpetrator or victim and the consequences are just as serious for every aspect of their lives. (Dooley, Pyzalski, \& Cross, 2009)

Information and awareness is important, as users who are aware of the dangers of the internet learn to be careful not to expose data and information that can be used by other people to harm them. Also, by being informed on cyber bullying, most of the time underage students report their problem to an adult and ask for appropriate help to manage it. The role of the school and of the parents is important both for the prevention and the treatment of the phenomenon, since through proper guidance the children can be protected and manage its negative consequences.(Feinberg \& Robey, 2009)

\section{Greek references}

\section{REFERENCES}

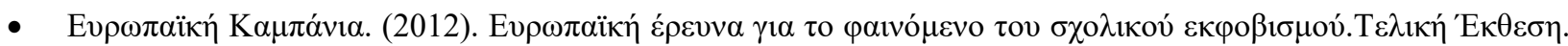

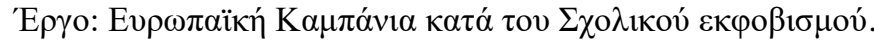

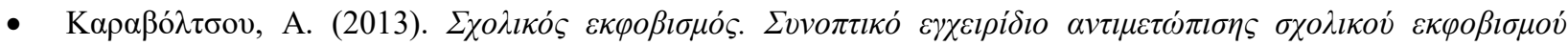

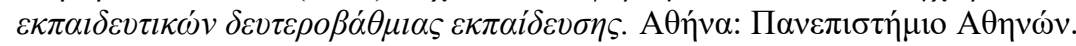

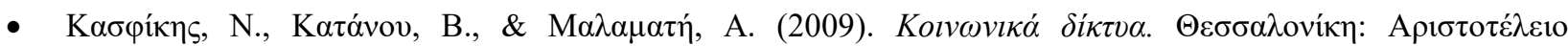

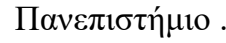

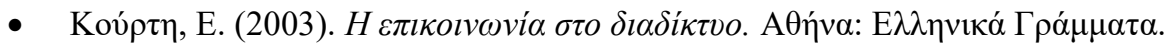

- $\quad$ Niко $\lambda$ ó

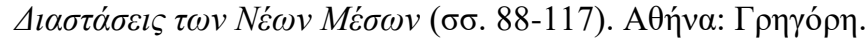

\section{Foreign references}

- $\quad$ Adams, C. (2010). Cyber bullying: How to make it stop. Instructor, 120 (2), pp. 44-49.

- Barringer-Brown, C. (2015). Cyber bullying among Students with Serious Emotional and Specific Learning Disabilities . Journal of Education and Human Development, 4 (2), pp. 50-56.

- $\quad$ Didden, R., Scholte, R. H., Korzilius, H., De Moor, J. M., Vermeulen, A., O'Reilly, M., et al. (2009). Cyber bullying among students with intellectual and developmental disability in special education settings. Developmental Neurorehabilitation, 12 (3), pp. 146-151.

- Dooley, J. J., Pyzalski, J., \& Cross, D. (2009). Cyber bullying versus face to face bullying: A theoretical and conceptual Review. Journal of Psychology, 217 (4), pp. 182-188.

- $\mathrm{Eu}$ Kids On Line. (2011). EU Kids Online: final report 2011.Retrived from http://eprints.lse.ac.uk/45490/1/EU\%20Kids\%20Online\%20final\%20report\%202011\%281sero\%29.pdf

- $\quad$ Feinberg, T., \& Robey, N. (2009). Cyber bullying: Intervention and Prevention Strategies. National Association of School Psychologists. Communique, 38 (4), pp. 1-4.

- Guckert, M. (2013). Understanding bystander perceptions of cyberbulluing in inclusive classroom settings. Fairfax, VA: George Mason University.

- Horakh, G. B. (2012). Cyber bullying and students with learning disabilities. New Jersey: Rowan University.

- Kowalski, R., Limber, S., \& Agatston, P. (2012). Cyber bullying in the Digital Age (Second Edition). United States: Wiley-Blackwell.

- Li, Q., Gross, P., \& Smith, P. (2012). Cyber bullying in the Global playground. United States: Blackwell Publishing Ltd. 
- McQuade, S. C., \& Sampat, N. (2008). Survey of internet and at-risk behaviors. Rochester, NY: Rochester Institute of Technology.

- Patchin, J., \& Hinduja, S. (2010). Cyber bullying and Self-Esteem. Journal of School Health, 80 (12), pp. 614621.

- Safe Line. (2015). Towards a safer internet for all. Retrived from http://www.safeline.gr/

- Smith, P. K., Mahdavi, J., Carvalho, M., \& Tippett, N. (2006). An investigation into cyber bullying, its forms, awareness and impact, and the relationship between age and gender in cyber bullying. Reserach Brief (RBX0306) .

- Ybarra, M., \& Mitchell, K. (2004). Youth engaging in online harassment: associations with caregiver-child relationships, Internet use, and personal characteristics. Journal of Adolescence, 27 (3), pp. 319-336.

\section{Translated Greek References}

- European Campaign. (2012) European research on the phenomenon on school bullying. Final Report. Project: Europe's Anti-Bullying Campaign

- Karavoltsou A. (2013) School bullying. Summary manual for treating school bullying for the educators in the secondary education. Athens: University of Athens

- Kasfikis, N. Katanou, B., \& Malamati A., (2009) Social Networks. Thessaloniki. Aristotle University.

- Kourti, E. (2003) Communication online. Athens. Hellinika Grammata.

- Nikolopoulos, D. (2009) Electronic Harassment : A modern threat. In A. Sofos, Pedagogical aspects of the new media (pg. 88-117), 